\title{
The rationale for pre-race aspirin to protect susceptible runners from sudden cardiac death during marathons: Deconstructing the Pheidippides conundrum
}

\author{
Arthur J. Siegel \\ Internal Medicine, McLean Hospital, Belmont, USA \\ Email: asiegel@partners.org \\ Received 22 May 2013; revised 27 June 2013; accepted 13 July 2013 \\ Copyright (C 2013 Arthur J. Siegel. This is an open access article distributed under the Creative Commons Attribution License, which \\ permits unrestricted use, distribution, and reproduction in any medium, provided the original work is properly cited.
}

\begin{abstract}
Objectives: While endurance exercise such as training for marathons is cardioprotective, cardiac arrests and sudden death occur in previously healthy runners during races predominantly in middle-aged males due to atherosclerotic heart disease. Recent evidence related to this problem is reviewed herein including epidemiologic studies and findings related to acute cardiac risk in asymptomatic middle-aged male runners during races. Method: Literature review related to the above. Findings: The risks of cardiac arrest and sudden death were 1 in 57,002 and 1 in 171,005 respectively in runners with a mean age of 49.7 years among $1,710,052$ participants in marathons in the United States since 1980. Atherosclerotic heart disease was the cause of death in over $90 \%$ of cases in two retrospective studies and a greater than two-fold increase in cardiac arrests was observed in middle-aged men in the latter half of a 10-year prospective registry beginning in the year 2000. Asymptomatic middle-aged male runners showed elevated biomarkers of inflammation such as interleukin-6, C-reactive protein together with procoagulant effects including in vivo platelet activation, indicating susceptibility to atherothrombosis. Conclusions: Antithrombotic prophylaxis is evidencebased by validated clinical paradigms to prevent cardiac arrest and sudden death in susceptibile marathon runners at high risk for atherothrombosis during races.
\end{abstract}

Keywords: Marathon Running; Cardiac Arrest; Acute Myocardial Infarction; Atherothrombosis; Aspirin Prophylaxis

\section{INTRODUCTION}

While endurance exercise such as marathon training is cardioprotective, an increased risk for sudden cardiac death during races has been demonstrated predominantly in middle-aged male participants. The conundrum of how runners at low resting cardiovascular risk become vulnerable to cardiac arrest during races is explored herein together with consideration of strategies for prevention.

\section{MATERIAL AND METHODS}

Review of medical literature related to the epidemiology and pathogenesis of sudden cardiac death in marathon runners during marathon races. Rates of cardiac arrest and sudden death were 1 in 57,002 and 171,005, respectively, in runners with a mean age of 49.7 years among 1,710,052 participants in United States marathons since 1980. Atherosclerotic heart disease was the cause of death in over $90 \%$ of cases in those over age 40 in two retrospective studies. A greater than two-fold increase in cardiac arrests events was observed in middle-aged males in the latter half of a 10-year prospective registry ending in the year 2010. Regarding pathogenesis, neutrophilia and elevated biomarkers of inflammation including interleukin-6 and C-reactive protein occurred in asymptomatic middle-aged males during races as a likely consequence of exertional rhabdomyolysis. Inflammation was accompanied by a hemostatic imbalance with procoagulant effects including elevated fibrinogen, D-dimer and in vivo activation of platelets, conferring a transient risk for atherothrombosis.

\section{DISCUSSION}

Because of concerns generated by the legacy of Pheidippides' sudden cardiac death in 490 B.C. (Figure 1), the first of many studies on Boston marathon runners in 1899 postulated an adverse effect of skeletal muscle injury on the heart [1]. Epidemiological evidence regarding such events during races in the modern era has re- 


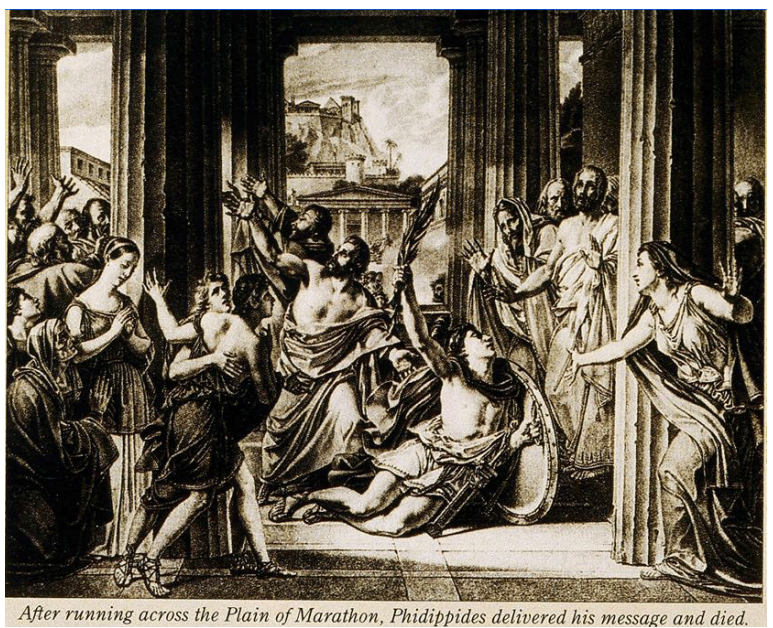

Figure 1. Pheidippides' sudden cardiac death in the Atheneum in 490 B.C. after declaring victory over the invading Persian army on the Plains of Marathon (by anonymous).

cently been published together with findings related to the underlying pathogenesis. Rates of cardiac arrest and sudden death were 1 in 57,002 and 171,005, respectively, in runners with a mean age of 49.7 years among 1,710,052 participants in United States marathons since 1980 [2]. Atherosclerotic heart disease was the cause of death in over $90 \%$ of runners over age 40 in two retrospective studies [2,3]. A greater than two-fold increase in cardiac arrests was observed in middle-aged males in the latter half of a 10-year prospective registry ending in 2010 [4].

Studies in asymptomatic middle-aged runners during races provide evidence that inflammation likely due to skeletal muscle injury activated atherothrombosis to account for the triggering of acute cardiac events during marathons in runners at low resting cardiovascular risk [5]. Elevated serum creatine kinase as an index of exertional rhabdomyolysis in runners after "hitting the wall" was accompanied by neutrophilia, increased interleukin6, C-reactive protein and matrix metallo-proteinase-9 [69]. Inflammation by this paradigm may render previously silent low-profile coronary atherosclerotic plaques vulnerable to rupture leading to acute myocardial infarction [10].

Additionally, asymptomatic runners demonstrated a hemostatic imbalance with procoagulant effects during races, including increased fibrinogen, elevated D-dimer and in vivo activation of platelets [11,12]. Biomarkers in runners at low resting cardiovascular risk morph into a profile creating a "perfect storm" for an acute coronary syndrome.

A report of 3 runners with acute myocardial infarctions due to plaque rupture after the 2011 Boston marathon validates these findings in asymptomatic runners as relevant to the pathogenesis of cardiac arrest and sudden death in the epidemiological studies [13].

Evidence for the triggering of sudden cardiac death during marathons by atherothrombosis in runners with previously silent coronary atherosclerosis invites consideration of strategies for prevention and treatment. Aspirin prophylaxis has been shown to prevent first myocardial infarctions in previously healthy individuals in the final report on aspirin prophylaxis in the Physicians' Healthy Study (PHS) in 1989, which finding has been confirmed in subsequent meta-analyses of randomized clinical trials [14,15].

Marathon runners are prime candidates for such treatment, which is currently endorsed by the American Heart Association for individuals at high, if transient, cardiovascular risk. A low-dose non-enteric coated aspirin taken even at the starting line can confer antithrombotic protection for the vulnerable period during and up to 24 hours after the race [16]. This strategy is evidencebased to prevent acute myocardial infarctions in asymptomatic runners whose Achilles' heel is the soft-coated low-profile atherosclerotic plaque which may morph into a culprit lesion.

What advice should we give susceptible runners receive regarding the cardiac risk of marathon races analogous to the Food and Drug Administration's advisory on the excess of sudden cardiac deaths with azithromycin in patients with cardiovascular disease [17]? We can endorse pre-race aspirin to reduce the number of tragic cardiac events during marathons according to the rationale shown in Figure 2 [18]. Ideally with consultation and approval by their physicians, runners should be advised to take pre-race low-dose aspirin to confer optimal protection during a vulnerable period of inflammation-induced atherothrombotic risk while also minimizing complications associated with continuous usage such as gastrointestinal bleeding. Once embraced by the marathon running community, the efficacy of prerace aspirin might be assessed prospectively among marathon runners at all levels of ability including those who may be at risk for accelerated coronary atherosclerosis from repetitive participation in races over many years [19].

While the jury may still be out on the question of direct adverse myocardial effects of intense endurance exercise, $[20,21]$ evidence for the triggering of cardiac arrest and sudden death effect during marathon running is

\begin{tabular}{l} 
IF A CARDIAC ARREST IN MARATHON RUNNERS DURING RACES \\
IS DUE TO ATHEROTHROMBOSIS \\
AND ASPIRIN IS EVIDENCE-BASED TO PREVENT FIRST \\
MYOCARDIAL INFARCTIONS IN HEALTHY PERSONS \\
MARATHON RUNNERS SHOULD TAKE ASPIRIN \\
TO PROTECT AGAINST SUDDEN CARDIAC DEATH \\
\hline
\end{tabular}

Figure 2. The rationale for pre-race low-dose aspirin by marathon runners. 
compelling. "To aspirin or not to aspirin" should no longer be a question for susceptible marathon runners for whom pre-race low-dose aspirin is already evidence-based as cardioprotective. This strategy deserves consideration to protect individuals from acute cardiac events during less intense recreational sports and perhaps especially for those previously sedentary who may initiate an exercise program as promoted by the "million hearts" initiative [22,23]. Pre-exercise low-dose aspirin looks like a "win-win" situation for all these scenarios. Hippocrates, who is said to have prescribed aspirin-like remedies in the time of Pheidippides, would likely concur with this strategy as a case in point of "First, do no harm".

\section{CONCLUSION}

The increased risk for cardiac arrest and sudden death during marathon running occurs predominantly in middle-aged males with previously silent coronary heart disease. The use of pre-race low-dose aspirin is evidencebased by validated clinical paradigms to protect such runners from acute cardiac events during races triggered by high, even if transient, atherothrombotic risk.

\section{REFERENCES}

[1] Williams, H. and Arnold, H.D. (1899) The effects of violent and prolonged muscular exercise upon the heart. Philadelphia Medical Journal, 3, 1233-1235.

[2] Mathews, S.C., Narotsky, D.L., Berbholt, D.L., et al. (2012) Mortality among marathon runners in the United States, 2000-2009. The American Journal of Sports Medicine, 40, 1495-1500. doi:10.1177/0363546512444555

[3] Webner, D., Duprey, K.M., Drezner, J.A., et al. (2012) Sudden cardiac arrest and death in United States Marathons. Medicine \& Science in Sports \& Exercise, 44, 18431845. doi:10.1249/MSS.0b013e318258b59a

[4] Kim, J.H., Malhotra, R., Chiampas, G., et al. (2012) For the RACER Study Group. The New England Journal of Medicine, 366, 130-142. doi:10.1056/NEJMoa1106468

[5] Siegel, A.J. (2012) Phaedippides Redux; reducing acute cardiac risk during marathon running. The American Journal of Medicine, 125, 630-635. doi:10.1016/j.amjmed.2011.11.008

[6] Siegel, A.J., Silverman, L.M. and Lopez, M.S. (1980) Creatine kinase elevations in marathon runners: Relationship to training and competition. Yale Journal of Biology and Medicine, 53, 275-279.

[7] Kratz, A., Lewandrowski, K.B., Siegel, A.J., et al. (2002) Effect of marathon running on hematological and biochemical laboratory parameters including cardiac markers. American Journal of Clinical Pathology, 118, 856-863. doi:10.1309/14TY-2TDJ-1X0Y-1V6V

[8] Siegel, A.J., Verbalis, J.G., Clement, S., et al. (2007) Hyponatremia in Marathon Runners due to Inappropriate Arginine Vasopressin Secretion. The American Journal of
Medicine, 120, 461.e11-461.e17.

[9] Saenz, A.J., Lee-Lewandrowsi, E., Wood, M.J., et al. (2006) Measurement of a plasma stroke biomarker panel and cardiac troponin $\mathrm{T}$ in marathon runners before and after the 2005 Boston marathon. American Journal of Clinical Pathology, 126, 1-5. doi:10.1309/D7QUF0HJMCYYYY5A

[10] Libby, P. and Crea, F. (2010) Clinical implications of inflammation for cardiovascular primary prevention. European Heart Journal, 31, 777-783. doi:10.1093/eurheartj/ehq022

[11] Siegel, A.J., Stec, J.J., Lipinska, I., et al. (2001) Effect of marathon running on inflammatory and hemostatic markers. American Journal of Cardiology, 88, 35-38. doi:10.1016/S0002-9149(01)01909-9

[12] Kratz, A., Wood, M.J., Siegel, A.J., et al. (2006) Effects of marathon running on platelet activation markers. Direct evidence for in vivo platelet activation. American Journal of Clinical Pathology, 125, 296-300.

[13] Albano, A.J., Thompson, P.D. and Kapur, N.K. (2012) Acute coronary thrombosis in Boston marathon runners. The New England Journal of Medicine, 366, 184-185. doi:10.1056/NEJMc1111015

[14] Steering Committee of the Physicians' Health Study Research Group (1989) Final report on the aspirin component of the ongoing Physicians' Health Study. The New England Journal of Medicine, 321, 129-135. doi:10.1056/NEJM198907203210301

[15] Hennekens, C.H. and Dalen, J.E. (2013) Aspirin in the treatment and prevention of cardiovascular disease: Past and current perspectives and future directions. The American Journal of Medicine, 126, 373-378. doi:10.1016/j.amjmed.2012.12.013

[16] Grosser, T., Fries, S., Lawson, J.A., et al. (2013) Drug resistance and pseudoresistance: an unintended consequence of enteric coated aspirin. Circulation, 127, 377-385. doi:10.1161/CIRCULATIONAHA.112.117283

[17] Ray, W.A., Murray, K.T., Hall, K., et al. (2012) Azithromycin and risk of cardiovascular death. The New England Journal of Medicine, 366, 1881-1890. doi:10.1056/NEJMoa1003833

[18] Weiler, R., Goldstein, M.A., Beasley, I., et al. (2012) What can we do to reduce the number of tragic cardiac events in sport? British Journal of Sports Medicine, 46, 897-898. doi:10.1136/bjsports-2012-091252

[19] Mohlenkamp, S., Lehmann, N., Breuckmann, F., et al. (2008) Running: The risk of coronary events: Relevance and prognostic relevance of coronary atherosclerosis in marathon runners. European Heart Journal, 29, 1903-1910. doi:10.1093/eurheartj/ehn163

[20] Yared, K. and Wood, M.J. (2009) Is marathon running hazardous to your cardiovascular health? The jury is still out. Radiology, 251, 3-5. doi:10.1148/radiol.2511090041

[21] Greche, A.L. (2013) Can intense endurance exercise cause myocardial damage and fibrosis? Current Sports medicine reports. Medicine \& Science in Sports \& Exercise, 12, 63-69.

[22] Marijon, E., Tafflet, M., Celermajer, D.S., Dumas, F., Pe- 
rier, M.C., Mustafic, H., Toussaint, J.F., Desnos, M., Fieu, M., Benameur, N., LeHeuzey, J.Y., Empana, J.P. and Jouven, X. (2011) Sports-related sudden death in the general population. Circulation, 124, 672-681.

doi:10.1161/CIRCULATIONAHA.110.008979
[23] Frieden, T.R. and Berwick, D.M. (2011) The "Million Hearts” initiative-Preventing heart attacks and strokes. The New England Journal of Medicine, 365, e27. doi:10.1056/NEJMp1110421 